\title{
Erratum to: Dye removal of AR27 with enhanced degradation and power generation in a microbial fuel cell using bioanode of treated clinoptilolite-modified graphite felt
}

\author{
Seyedeh Nazanin Kardi ${ }^{1}$. Norahim Ibrahim ${ }^{1}$ - Ghasem Najafpour Darzi ${ }^{2}$. \\ Noor Aini Abdul Rashid ${ }^{1}$ • José Villaseñor ${ }^{3}$
}

Published online: 15 July 2017

(C) Springer-Verlag GmbH Germany 2017

\section{Erratum to: Environ Sci Pollut Res}

DOI 10.1007/s11356-017-9204-1

The original publication of this paper contains an error.

The correct image for Fig. 3e is shown below:

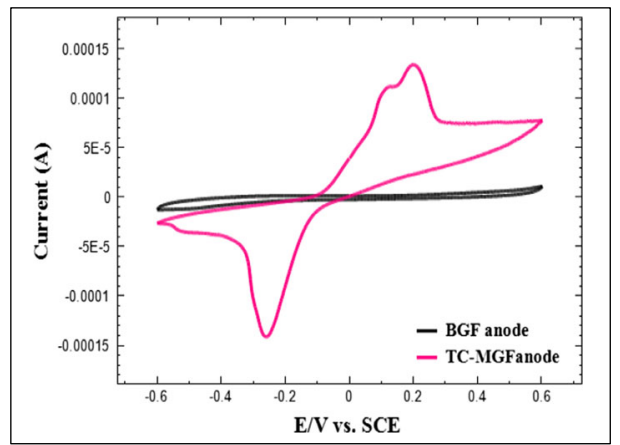

The original article was revised.

The online version of the original article can be found at http://dx.doi.org/ 10.1007/s11356-017-9204-1

Seyedeh Nazanin Kardi

nkseyedeh2@live.utm.my

Norahim Ibrahim

norahim@fbb.utm.my

1 Department of Biosciences and Health Sciences, Faculty of Biosciences and Medical Engineering, Universiti Teknologi Malaysia, 81310 Skudai, Johor, Malaysia

2 Biotechnology Research Laboratory, Faculty of Chemical Engineering, Babol Noshirvani University of Technology, Babol 47148-71167, Iran

3 Department of Chemical Engineering, Institute for Chemical and Environmental Technology, University of Castilla-La Mancha, Ciudad Real, Spain 